\section{Trakya Eğitim Dergisi}

Cilt 8, Sayı 3

May1s 2018, 629-640

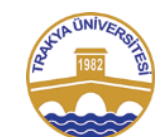

ISSN: 2630-6301
Trakya Journal of Education

Volume 8, Issue 3

May 2018, 629-640

Doi: $10.24315 /$ trkefd.316512

Geliș Tarihi: 27.07.2017

Yayına Kabul Tarihi: 20.09.2017

\title{
Çevrimiçi Öğretime Hazırbulunuşluk Anketinin Türkçeye Uyarlanması ${ }^{1}$
}

\section{Turkish Adaptation of Readiness to Teach Online Survey}

\author{
Tuğba HOŞGÖRÜR, Müge ADNAN
}

Öz: Bu çalışmada, Chi (2015) tarafından geliştirilen Çevrimiçi Öğretime Hazırbulunuşluk Anketinin Türkçeye uyarlanması amaçlanmıştır. Araştırmanın çalışma grubunu, 2015-2016 öğretim yılında Muğla S1tk1 Koçman Üniversitesi'nde görev yapan 138 öğretim elemanı oluşturmuştur. Çevrimiçi Öğretime Hazırbulunuşluk Anketi öğrenme öğretme süreci, sosyal bağ ve öğrenci katılımı, öğretim elemanlarına teknoloji desteği, ders tasarımı ve öğretimsel tasarım ve ölçme ve değerlendirme olmak üzere beş ayrı bölümden oluşmaktadır. Ankette 63 seçenekli, 13 açık uçlu ve 2 tane de yapılandırılmış maddeler içinden seçimler yapılarak yanıtlanacak sorular bulunmaktadır. Anketteki nicel veriler sağlayan maddelerin güvenirliği için hesaplanan Cronbach's Alfa iç tutarlık katsayısı ,91 olarak bulunmuştur. Nitel verilerin analizinden elde edilen sonuçların alan uzmanları tarafindan yapılan analizleri sonucunda, katılımcıların ankete verdikleri yanıtların, sorularda istenilen bilgileri doğrudan karşıladığı görülmüştür. Elde edilen bulgulara dayanarak; uyarlanan anketin Türkiye'deki yükseköğretim kurumlarında uygulanabilecek geçerli ve güvenilir bir ölçme aracı olduğu söylenebilir.

Anahtar sözcükler: Çevrimiçi ögrretim, çevrimiçi öğretime hazırbulunuşluk anketi, uyarlama.

\begin{abstract}
This study aims to adapt Chi's (2015) Readiness to Teach Online Survey into Turkish context. Participants of the study are 138 faculty members at Muğla Sitkı Koçman University, Turkey, during the 2015-2016 academic year. The Readiness to Teach Online Survey consists of 63 Likert-type items, 13 open-ended questions, and two questions with structured items under five dimensions: Teaching and Learning, Social and Student Engagement, Faculty and Technology Support, Course Development and Instructional Design, Evaluation and Assessment. Cronbach's alpha internal consistency coefficient for quantitative items in the survey has been found to be .91 . Analyses of answers to open-ended questions by subject matter experts have indicated that participants' answers are directly associated with the information anticipated from these questions. Based on the obtained findings, it is possible to say that the Turkish adaptation of the Readiness to Teach Online Survey is a valid and reliable measurement tool for higher education institutions in Turkey.
\end{abstract}

Keywords: Online teaching, readiness to teach online survey, adaptation

\section{Introduction}

\section{EXTENDED ABSTRACT}

When a higher education institution has started the process of opening online distance education programs or integrating online technologies into on-campus courses, it is safe to assume that not all faculty members will accept and embrace this new teaching-learning environment, and, maybe more importantly, that they will be ready to use this new environment. Although technological infrastructure is a crucial aspect in such change processes, the more challenging aspects are the appropriate electronic content, pedagogically acceptable course design, and the readiness of faculty members being at the core of the teaching-learning environment. Prepared and enthusiastic faculty members ready to embrace this new world are the key to success for any organization in the process of adopting online technologies for the delivery of education. Online teaching-learning environments are somewhat different from

\footnotetext{
${ }^{1}$ Bu çalışma, 31 Mayıs-3 Haziran 2016 tarihlerinde Muğla Sıtkı Koçman Üniversitesi’nde düzenlenen 3. Uluslararası Avrasya Eğitim Araştırmaları Kongresi'nde sunulmuş olan sözlü bildirinin genişletilmiş halidir.
} 
traditional ones (Totaro, Tanner, Noser, Fitzgerald \& Birch, 2005), and achievement of such challenging initiatives depends on high-quality delivery by faculty members (Tabata \& Johnsrud, 2008). In this regard, it is necessary to consider not only faculty members' perceptions of efficiency of online learning, but also their potential hesitance and anxiety regarding online technologies used in such learning environments.

Online Learning Consortium's 2016 report underlines the rather skeptical approach of faculty members towards online distance education, despite the ever-increasing usage of online technologies in schools for more than a decade. Furthermore, the report states that failure to convince faculty members regarding the 'value' of online education as one of the main reasons behind not being able to achieve the wellanticipated success of online technologies in education (Allen, Seaman, Lederman \& Jaschik, 2016). Several studies indicate that faculty members' prior exposure to online learning environments, either as instructors or learners, positively transforms their attitude towards using these technologies (Adnan \& Boz, 2015; Allen, Seaman, Poulin \& Taylor Straut, 2012; Gold, 2001). Initial studies on the attitudes of faculty members towards distance education focus on technology use, competencies, workload, institutional support and quality of teaching (Lee \& Busch, 2005; Tabata \& Johnsrud, 2008), while recent studies focus more on administrators' views, quality of courses and programs, institutional support provided to faculty members, and technological competencies of faculty members (Allen et al., 2016; Palloff \& Pratt, 2011; Singleton \& Session, 2011). A good understanding of faculty members' attitudes and level of readiness for online distance education is a crucial input for strategic planning by higher education institutions in their effort for opening or sustaining online distance education programs or courses.

\section{Method}

This study aims to adopt Chi's (2015) Readiness to Teach Online Survey, which was developed for a similar purpose, into Turkish context. The participants of the study are 138 faculty members of Muğla S1tk1 Koçman University who were actively teaching during the 2016-2017 academic year, who volunteered to take part in the study. The original survey is comprised of structured and open-ended questions, enabling collection of quantitative and qualitative data. Two items in the survey (one for informed consent, and another for academic title) were embedded within a Personal Information section in the Turkish adaptation of the survey, and the number of items dropped to 31. Researchers translated the original survey from English into Turkish separately, compared the translated versions, and reached an agreement on the final version. Both the original survey and the translated version were then reviewed by three linguists and two subject-matter experts, and revised accordingly based on obtained recommendations. The Turkish version of the survey was finalized following an additional review by two more linguists. Lastly, the final version was administered to five faculty members at five different academic levels as a pilot implementation in order to assess understandability of the items. The survey was revised based on recommendations of the pilot participants.

\section{Results and Discussion}

The final adapted version of the Readiness to Teach Online Survey consists of 63 Likert-type items, 13 open-ended questions, and two questions with structured items under five dimensions: Teaching and Learning, Social and Student Engagement, Faculty and Technology Support, Course Development and Instructional Design, Evaluation and Assessment. Cronbach's alpha internal consistency coefficient for quantitative items in the survey has been found to be .91 . Analyses of answers to open-ended questions by subject-matter experts have indicated that participants' answers are directly associated with the information anticipated from these questions. Based on the obtained findings, it is possible to say that the Turkish adaptation of the Readiness to Teach Online Survey is a valid and reliable measurement tool for higher education institutions in Turkey.

\section{GİRIŞ̧}

Bilgi ve iletişim teknolojilerinde yaşanan gelişmeler neticesinde, teknoloji artık günlük yaşamın ayrılmaz bir parçası olmuştur. Teknolojinin en büyük etkilerinden biri de, öğretme-öğrenme 
ortamlarında görülmüş̧ür. Bilgi ve iletişim teknolojilerinin sağladığı kolay erişim ve esneklik, eğitim örgütlerinin teknolojiyi farklı biçimlerde işe koşmalarına yol açmış; bu değişim özellikle öğrencilerin demografik özelliklerindeki farklılıklar, lojistik problemler ve yüzyüze öğretimin belli kalemlerinde maliyet yüksekliği gibi nedenlerle yükseköğretim kurumlarında gözle görülür bir noktaya gelmiştir. Günümüzde yükseköğretim kurumlarındaki uygulamalar ön lisans, lisans ve lisansüstü düzeylerde tamamen çevrimiçi programlar açılması, bazı derslerin çevrimiçi platforma taşınması veya kampüs derslerinin çevrimiçi teknolojilerle desteklenmesinin yanı sıra ders materyallerine açık erişim ya da kitlesel açık çevrimiçi dersleri içermektedir. Uygulamanın türü ne olursa olsun, nitelikli çevrimiçi öğrenme olanakları için doğru, planlı ve sistemli bir geçiş süreci yaşanması gerekmektedir. Bu geçiş sürecinde örgütün sahip olduğu veya öngördüğü teknolojik altyapı ve içerik altyapısının ötesinde, bu değişimin örgütsel düzeyde ve özellikle de öğrenme-öğretme sürecinin kalbinde yer alan öğretim elemanları tarafından benimsenmesi önemlidir. Nitekim öğretim elemanları değişimin asıl uygulayıcılarıdır (Hoşgörür, 2016). 'İnsan' faktörü, çevrimiç̧i öğrenim ve öğretimin kabulü önündeki en önemli engellerden biri olarak gösterilmektedir (Albion, Tondeur, Forkosh-Baruch ve Peeraer, 2015; Stein, Shephard ve Harris, 2011). Tüm paydaşların aktif olarak yer alıp katkı sağlayacağı böyle bir sürecin aceleye getirilmesi ise alışkanlıklarını terk edip geleneksel sınıf ortamından yeni teknolojiler ve yeni pedagojiler gerektiren yepyeni ve alışılmadık bir öğretme-öğrenme ortamına taşınmak durumunda kalan öğretim elemanlarının direnciyle karşılaşılmasına yol açabilir (Madden, 2008). Bu nedenle, her türlü çevrimiçi uygulamanın eğitim sürecine dahil edilmesiyle başarının yakalanması, öğretim elemanlarının ve kurumun hazırbulunuşluğu ile ilgili kapsamlı verilerin toplanarak, sürecin etkili yönetilmesine bağlıdır.

Çevrimiçi öğretime geçişte öğretim elemanlarına ileri düzey eğitim ve destek sağlanmasına gereksinim vardır (Bates, 2000). Bu geçiş sürecinde etkili sonuç alabilmek amacıyla kampüs derslerini çevrimiçi teknolojilerle desteklemek veya çevrimiçi uzaktan eğitim ders ve programlarını açmak ve yaygınlaştırmak isteyen yükseköğretim kurumlarının bünyesindeki öğretim elemanlarının çevrimiçi uzaktan eğitime olan tutumlarını ve hazırbulunuşluk düzeylerinin belirlenmesi, stratejik planlama çalışmalarına da kaynak sağlaması açısından önemlidir. Bu çalışmada, böyle bir amaç doğrultusunda, Chi (2015) tarafından geliştirilen Çevrimiçi Öğretime Hazırbulunuşluk Anketinin Türkçeye uyarlanması amaçlanmıştır.

\section{1. Çevrimiçi Teknolojilerin Öğrenme-Öğretme Ortamlarıyla Bütünleştirilmesi Sürecinde Öğretim Elemanlarının Yeri}

Bir yükseköğretim kurumunda çevrimiçi uzaktan eğitim programları açarken veya çevrimiçi teknolojilerin derslerde kullanılmasına yönelik çalışmalar başlatırken, tüm öğretim elemanlarının bu yeni öğretme-öğrenme ortamını hemen benimseyeceklerini ve daha da önemlisi bu ortamı kullanmak için yeterince hazırlıklı olduklarını varsaymak mümkün değildir. Bu tür dönüşümlerde teknolojik altyapı önemli rol oynuyor olsa da (Özgür, 2013), elektronik ders materyallerinin hazırlanması, ders tasarımının pedagojik standartlara uygun olması ve öğretme-öğrenme ortamlarının merkezinde yer alan öğretim elemanlarının hazırbulunuşluğu gibi eğitim sürecine ilişkin değişkenler karşımıza çıkmaktadır.

Çevrimiçi teknolojileri derslerinde kullanmaya veya çevrimiçi uzaktan eğitim programları başlatmaya karar veren bir kurumun başarı elde edebilmesi için, bu yeni dünyayı olumlu bir biçimde karşılayıp benimsemeye hazır öğretim elemanlarının varlığı, anahtar rol oynayacaktır. Nitekim çevrimiçi teknolojiler ile ilgili yapılan çoğu çalışma, bunların öğrencilerin öğrenmesinde öğretmenlerden daha fazla etkili olamadığını göstermektedir (Hoşgörür, 2011). Bu durum, teknolojilerin eğitim ortamlarına sağlayabileceği potansiyel faydaların öğrencilerin öğrenmesi lehine kullanılamadığı anlamına gelmektedir. Çevrimiçi öğrenme-öğretme ortamları, geleneksel öğretme-öğrenme ortamlarından oldukça farklıdır (Totaro, Tanner, Noser, Fitzgerald ve Birch, 2005) ve bu tür girişimlerin başarısı nitelikli öğretim yapan öğretim elemanlarına bağlıdır (Tabata ve Johnsrud, 2008). Bu kapsamda, öğretim elemanlarının çevrimiçi öğrenmenin etkililiğine ilişkin görüşlerine ek olarak, bu öğrenme ortamlarında kullanılan çevrimiçi teknolojilere dair korku, kaygı ve gereksinimlerinin de dikkate alınmas1 gerekmektedir.

Çevrimiçi uzaktan eğitimin geliştirilmesi için lider mesleki kuruluşlardan biri olan Online Learning Consortium'un 2016 yılında yayınladığı rapora göre, çevrimiçi teknolojiler on yılı aşkın 
süredir okullarda giderek yaygınlaşan bir şekilde kullanılmasına rağmen, öğretim elemanları çevrimiçi uzaktan eğitime hala şüpheyle yaklaşmaktadırlar. Dahası, raporda, öğretim elemanlarının çevrimiçi eğitimin değeri konusunda ikna edilememiş olmasının, istenilen başarının sağlanamamasının temel nedenlerinden biri olduğu ifade edilmektedir (Allen, Seaman, Poulin ve Taylor Straut, 2016, s. 26). Alanyazındaki çalışmalar, öğretim elemanlarının daha önceden öğrenci veya öğretim elemanı olarak çevrimiçi öğrenme ortamlarında deneyimler yaşamış olmalarının, bu teknolojileri kullanma konusunda tutumlarını olumlu yönde değiştirdiğine işaret etmektedir (Adnan ve Boz, 2015; Allen, Seaman, Lederman ve Jaschik, 2012; Gold, 2001).

Öğretim elemanlarının uzaktan eğitime yönelik tutumlarını konu alan ilk çalışmalar; teknoloji kullanımı, yeterlikler, iş yükü, kurumsal destek ve öğretim kalitesi gibi konulara yoğunlaşırken (Lee ve Busch, 2005; Tabata ve Johnsrud, 2008), son dönemde yapılan çalışmalar, konuya ilişkin yönetici görüşleri, ders ve programların niteliği, öğretim elemanlarına sağlanan kurumsal destek ve öğretim elemanlarının teknoloji yeterliklerine odaklanmaktadır (Allen ve diğ., 2016; Palloff ve Pratt, 2011; Singleton ve Session, 2011). Lee ve Busch'un (2005) öğretim elemanlarının uzaktan eğitim sürecinde yer alma istekliliği ile ilgili çalışmasında elde ettiği sonuçlardan biri, öğretim elemanlarının istekli olma halini etkileyen düşünce ve deneyimlerine ilişkin bilgilerin üniversitelerin uzaktan eğitim inisiyatiflerini yapılandırmalarında ve sürdürmelerinde önemli bir girdi olacağıdır. Chi'nin de (2015) işaret ettiği gibi, Lee ve Busch'un (2005) bulguları, Knowles'un (1984) yetişkin eğitimi varsayımlarını (bilme gereksinimi, öğrenen deneyimi, benlik algısı, yönelim, güdülenme ve hazırbulunuşluk) yansıtmaktadır. Tabata ve Johnsrud'un (2008) Rogers'ın yeniliklerin yayılımı kuramı çerçevesinde öğretim elemanlarının teknoloji kullanımı ve uzaktan eğitime karşı tutumları ve sürece katılımlarını araştıran geniş ölçekli çalışmasında ise, geleneksel olmayan öğretim ortamlarına katılan öğretim elemanlarının uzaktan eğitimi kendi çalışma stilleriyle ilişkilendirme eğiliminde oldukları ifade edilmiştir. Yapılan çalışmalar, öğrencilere yardım etme, daha geniş kitlelere ulaşma, esneklik ve öz-tatmin gibi içsel güdüleyicilerin yanı sıra ders yükü, ek ödemeler, tanınma, ödül sistemi ve idari destek gibi dışsal güdüleyicilerin de öğretim elemanlarının uzaktan eğitime yönelik tutumlarını etkilediğini göstermiştir (Chi, 2013; Lorenzetti, 2011; Singleton ve Session, 2011).

\section{2. Çevrimiçi Öğretime Hazırbulunușluk}

Dada (2006), elektronik hazırbulunuşluğu bir ülke, bir ulus veya bir kurumun bilgi ve iletişim teknolojilerini kullanma ve bu teknolojilerden faydalanma açısından ne kadar hazır, istekli ve yeterli olduğunun ölçümünden edinilen bilgi olarak tanımlamaktadır. Eğitim ve öğretim özelinde ele alındığında ise e-öğrenme veya çevrimiçi öğrenmeye hazırbulunuşluk, "bir örgütün e-öğrenme deneyimleri veya eylemleri için zihinsel ve fiziksel olarak hazırlıklı olma hali" olarak tanımlanmaktadır (Borotis ve Poulymenakou, 2004). Çevrimiçi öğrenmeye hazırbulunuşluğun öğrenme çıktıları ve çevrimiçi öğrenmenin niteliğini etkileyen faktörlerden biri olması nedeniyle, bu konuda ulusal ve uluslararası alanyazında özellikle öğrencilerin çevrimiçi öğrenmeye hazırbulunuşluğunu çeşitli boyutlardan inceleyen pek çok çalışma bulunmaktadır (Çakır ve Horzum, 2015; Kaymak ve Horzum, 2013; Shraim ve Khlaif, 2010; Smith, Murphy ve Mahoney, 2003; Warner, Christie ve Choy, 1998; Watkins, Leigh ve Triner, 2004; Yağc1, Sırakaya ve Özüdoğru, 2015).

Türkiye'de uzaktan eğitimden bahsedilmeye 1924 yllında John Dewey'in önerisiyle başlanmış, ancak zamanın koşulları nedeniyle 1960'lara kadar uygulamaya geçilememiştir. 1990'lardan sonra bilgi ve iletişim teknolojilerinin yaygınlaşmasının doğal bir sonucu olarak internet tabanlı uzaktan eğitim uygulamaları üniversitelerde çeşitli şekillerde kullanılmaya başlanmıştır. İnternetin üniversitelerde günlük yaşamın bir parçası olmasıyla birlikte, çevrimiçi teknolojilerin sağladığı zaman ve mekan esnekliğinin yanı sıra, yer ve öğretim elemanı ihtiyacı gibi sorunlara getirdiği çözümler ile öğrenme ortamlarını zenginleştirmesi gibi üstünlükleri yükseköğretim kurumlarını harekete geçirmiştir. $\mathrm{Bu}$ nedenle pek çok üniversite internet tabanlı uzaktan eğitim programları açmış veya kampüs derslerinin bazılarını tamamen bazılarını da kısmen çevrimiçi teknolojilerle desteklemeye başlamışlardır.

$\mathrm{Bu}$ geçiş sürecinde bazı üniversiteler teknolojik altyapı ve örgütsel hazırbulunuşluğa yönelik çalışmalar gerçekleştirmişlerdir. Bu çalışmalar içerisinde, doğrudan öğretim elemanlarının uzaktan eğitim veya çevrimiçi öğretime dair görüşlerinin, tutumlarının veya hazırlıklarının incelendiği araştırma çalışmaları da yer almaktadır. Akaslan ve Law (2011) Türkiye'de elektrik-elektronik eğitimi 
programlarında çalışan 417 öğretim elemanının e-öğrenmeye hazır olma durumlarını ve eğitim gereksinimlerini araştırmıştır. Araştırmada, Kaur ve Abas'ın (2004) e-öğrenme kavramsal modeli temelinde hazırlanan ve 41 sorudan oluşan bir e-öğrenme hazırbulunuşluk anketi kullanılmıştır. Akaslan ve Law'un (2011) geliştirdiği ankette, 'e-öğrenmeye hazırbulunuşluk', 'e-öğrenmenin kabulü' ve 'eöğrenme eğitimi' olmak üzere üç boyut bulunmaktadır. İlk boyuttaki maddeler ağırlıklı olarak öğretim elemanlarının teknoloji kullanım yeterliklerine odaklanmış olup, üst yönetimin e-öğrenmeye bakışıyla ilgili iki soru bulunmaktadır. İkinci boyutta öğretim elemanlarının e-öğrenmeye ilişkin genel görüşleri incelenmekte, son boyutta ise üniversitenin sağladığ 1 olanaklar ve eğitim gereksinimine ilişkin sorular yer almaktadır. Ankette teknoloji entegrasyonuna ilişkin bir açık uçlu soru bulunmaktadır. Akaslan ve Law (2011), araştırma sonucunda katılan öğretim elemanlarının e-öğrenme konusunda olumlu görüşlere sahip olduğu sonucuna ulaşmışlardır. Aynı anketi uyarlayarak kullanan Soydal, Alır ve Ünal (2012) ise, Hacettepe Üniversitesi Eğitim Fakültesi öğretim elemanlarının e-öğrenmeye hazırbulunuşluklarını incelemişlerdir. Çalışma sonucunda, öğretim elemanlarının e-öğrenmeye ilişkin algılarının çok olumlu olmadığı, ancak bu konuda eğitilmek için katılımcıların istekli olduğu ifade edilmiştir.

Süer ve diğerleri (2005) tarafından Gazi Üniversitesi'nin uzaktan eğitim potansiyelinin değerlendirilmesi amacıyla yapılan betimsel araştırmada, üniversitenin insan gücü kaynakları açısından uzaktan eğitime hazırbulunuşluk düzeyleri belirlenmiş ve üniversitede hangi alanda ve ne tür uzaktan eğitim derslerine gereksinim olduğu ortaya konmuştur. Araştırmada iki veri toplama aracı kullanılmıştır. Öğretim elemanlarının hazırbulunuşluk düzeyini belirlemek için Ağır ve diğerleri (2007) tarafından geliştirilen 'Uzaktan Eğitim Tutum Ölçeği' kullanılmıştır. Ölçekte, öğretim elemanlarının uzaktan öğrenmeye karşı tutumları, uzaktan öğrenmenin temel özelliklerine dayalı sorularla ölçülmüştür. Araştırmada kullanılan ikinci veri toplama aracı ise öğretim elemanlarının uzaktan öğretim sürecinde hangi süreçlere katkı sağlayabileceklerini inceleyen iki boyutlu standart bir ölçektir. Bu ölçekte ise içerik geliştirme, öğretimsel yazılım tasarlama ve geliştirme, ses ve video dosyaları hazırlama ve tele/video-konferans yapabilme gibi süreçlere öğretim elemanlarının ne kadar katk1 verebileceğine ilişkin sorular yer almaktadır. Araştırmacılar tarafından geliştirilen Uzaktan Eğitim Tutum Ölçeği'nden elde edilen bulgular, uzaktan eğitime güven boyutunda öğretim elemanlarının tereddütlü olduklarını, uzaktan eğitime ilgi duyduklarını ancak bu ilginin yüksek düzeyde olmadığını göstermiştir.

Süer ve diğerleri'nin çalışması (2005), aynı veri toplama araçları kullanılarak, Adnan (2012) tarafından Muğla Sitkı Koçman Üniversitesi'nin uzaktan eğitime hazırbulunuşluğunun araştırılması amacıyla tekrarlanmıştır. Farklı bölümlerden 268 öğretim elemanının katıldığı çalışmada da benzer sonuçlar elde edilmiş, katılımcıların uzaktan eğitime olumlu ancak temkinli yaklaştığı belirlenmiştir. Üniversitenin uzaktan eğitim planlamasına girdi teşkil etmek üzere gerçekleştirilen çalışma sonucunda, öğretim elemanlarına eğitim ve içerik geliştirmeye ek olarak teknik ve idari açıdan da sürekli yardım sağlayacak kapsamlı bir kurumsal destek sisteminin oluşturulması gerektiği sonucuna varılmıştır. Söz konusu çalışmadan edinilen bilgiler, üniversite bünyesinde 2012 yılında başlatılan uzaktan eğitim faaliyetlerinin planlanmasında temel olarak kullanılmıştır.

\section{3. Çevrimiçi Öğretime Hazırbulunuşluk Anketi}

Çevrimiçi Öğretime Hazırbulunuşluk Anketi (Readiness To Teach Online Survey), Denver Üniversitesi Morgridge Eğitim Fakültesi'nin stratejik planlama ihtiyacını karşılayacak tüm boyutları içeren bir ölçüm aracı olarak Chi (2015) tarafından geliştirilmiştir. Aracın geliştirilmesinde uluslararası platformda çevrimiçi öğrenmenin lider kuruluşlarından Online Learning Consortium'un (OLC) beşli kalite çerçevesi (öğrenmenin etkililiği, maliyet etkinlik, erişim, öğreten memnuniyeti ve öğrenen memnuniyeti) ile çevrimiçi programları değerlendirme çerçevesindeki sınıflandırma temelinde alanyazındaki diğer ölçme araçlarının incelenmesi sonucunda ortaya çıkmıştır.

Ankette yer alan nitel ve nicel sorular, beş boyut altında gruplandırılmıştır: 


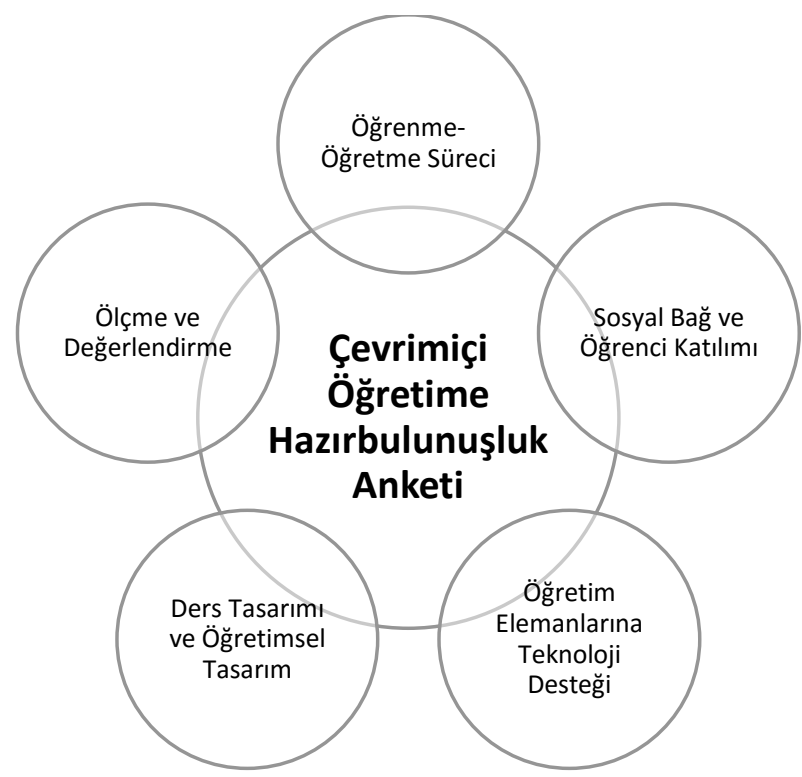

Şekil 1. Çevrimiçi Öğretime Hazırbulunuşluk Anketi Boyutları

Anketin Öğrenme-Öğretme Süreci boyutunda öğretim elemanlarının teknoloji kullanma yeterlikleri, teknolojiye ve çevrimiçi ögrenmeye yönelik algıları ile çevrimiçi teknolojileri kullanma konusunda onları güdüleyecek unsurları incelenmektedir. Bu boyut altında öğretim elemanlarının çevrimiçi teknolojileri kullanmaya dair kurumsal beklentileri de yer almaktadır. Sosyal Bă̆ ve Öğrenci Katılımı boyutunda, öğretim elemanlarının çevrimiçi teknolojileri kullanırken öğrenci etkileşimini nasıl sağlayacakları ve çevrimiçi öğrenme ile öğrencilerle arada nasıl bağ kuracağına dair algı ve yeterlikleri konusunda bilgi sahibi olmaya yönelik maddeler bulunmaktadır. Öğretim Elemanlarına Teknoloji Desteği boyutunda, öğretim elemanlarının teknoloji kullanma durumları, sınıfta hangi teknolojileri sıklıkla kullandıkları, teknoloji kullanma konusundaki altyapıları ve üniversite tarafindan sağlanan mesleki gelişim olanakları konusundaki görüşleri irdelenmektedir. Ders Tasarımı ve Öğretimsel Tasarım boyutunda, öğretim elemanlarının derste kullandıkları öğretim strateji, yöntem ve teknikleri ile derslerde çevrimiçi teknolojileri kullanma durumları ve yeterlik düzeylerine yönelik açık ve kapalı uçlu sorular yer almaktadır. Son olarak Ölçme ve Değerlendirme boyutunda ise öğrencilerin öğrenme durumlarını izlemede kullanılan teknolojiler ve öğrenme sürecinin değerlendirilmesinde teknoloji kullanımına ilişkin açık uçlu sorular yer almaktadır.

Chi’nin (2015) geliştirdiği anketin en önemli özellikleri, örgütsel stratejik planlama sürecine yönelik olarak uluslararası alanda kabul görmüş kalite ölçütleri temelinde hazırlanmış olması, altyapı, öğreten ve öğrenen bakış açılarının tümüne yer vermesi ve her bir boyutun altında öğretim elemanlarının görüş ve algılarına ek olarak öğretim elemanlarının kurumsal beklentilerinin de irdelendiği sorular olmasidir.

\section{YÖNTEM}

$\mathrm{Bu}$ bölümde araştırmanın çalışma grubunun özellikleri, ölçme aracının Türkçeye uyarlanması işlem basamakları ile geçerlik ve güvenirlik analizlerine ilişkin bilgiler sunulmuştur. Araştırmada, Chi (2015) tarafından geliştirilen Çevrimiçi Öğretime Hazırbulunuşluk Anketi (Readiness To Teach Online Survey), Türkçeye uyarlanmıştır.

Araştırmacıdan, anketin Türkçeye uyarlanabilmesi için gerekli iznin alınmasının ardından başlatılan araştırmanın çalışma grubunu, 2015-2016 öğretim yılında Muğla Sıtkı Koçman Üniversitesi'nde görev yapan ve çalışmaya gönüllü olarak katılan 138 öğretim elemanı (Profesör, Doçent, Yardımcı Doçent, Okutman, Öğretim Görevlisi) oluşturmuştur. Anketlerin öğretim elemanlarına ulaştırılması araştırmacılar tarafından yüz yüze görüşmeler yapılarak gerçekleştirilmiş ve bu görüşmeler sırasında anketin gerçekleştirilme amacı öğretim elemanlarına açıklanarak, görüşlerini paylaşmaları istenmiştir. Anket 165 kişiye ulaştırılmış ve geri dönen 139 anketten kullanılabilir durumda olan 138 anket ile analizler yapılmıştır. Araştırmaya katılan 
öğretim elemanlarının \%24,64'ü okutman ( $\mathrm{n}=34), \% 9,42$ 'si öğretim görevlisi $(\mathrm{n}=13), \% 37,68$ 'i yardımcı doçent $(n=52), \% 20,29$ 'u doçent $(n=28), \% 7,97$ 'si profesördür $(n=11)$. Öğretim elemanlarının \%54,35'i kadın ( $n=75), \% 45,65$ 'i erkektir ( $n=63)$. Öğretim elemanlarının kurumda çalışma süreleri 1 ile 24 yıl arasında değişmektedir. Öğretim elemanlarının; \%3,62'si Edebiyat $(\mathrm{n}=5), \% 52,17$ 'si Eğitim $(\mathrm{n}=72), \% 7,25$ 'i İktisadi ve İdari Bilimler $(\mathrm{n}=10), \% 5,80$ 'i Sağlık Bilimleri $(n=8), \% 0,73$ 'ü Spor Bilimleri $(n=1), \% 2,17$ 'si Teknoloji $(n=3)$ ve \%5,07'si Turizm $(n=7)$ Fakültelerinde, \%1,45'i Sağlık Hizmetleri Meslek Yüksekokulunda (n=2), \%4,35'i Atatürk ilkeleri ve İnk1lap Tarihi (n=6), \%217'si Enformatik (n=3), \%1,45'i Türk Dili (n=2) ve \%13,77'si Yabancı Diller Eğitimi (n=19) Bölümlerinde görev yapmaktadır.

Çevrimiçi Öğretime Hazırbulunuşluk Anketi'nin orijinal formu sırasıyla, öğrenme öğretme süreci, sosyal bağ ve öğrenci katılımı, öğretim elemanlarına teknoloji desteği, ders tasarımı ve öğretimsel tasarım ve ölçme ve değerlendirme olmak üzere beş ayrı bölümden oluşmaktadır. Orijinal ankette, ilki katılımcının bilgilendirilmiş onay formu ve sonuncusu da katılımcının unvanı olmak üzere toplam 33 madde bulunmaktadır. Anket, Likert tipi derecelendirilerek yapılandırılmış sorular yanında, açık uçlu sorulardan da oluşması itibariyle nitel ve nicel verilerin birlikte toplanabilmesini olanaklı kılmaktadır. Anketin, Türkçeye uyarlanmış halinde toplam 31 madde bulunaktadır. Uyarlama çalışmasının ilk bölümünde katılımcıların unvan bilgileri, kişisel bilgiler ile ilgili bölümde istendiği ve bilgilendirilmiş rıza formu ayrı bir madde olarak ele alınmadığı için; sözü edilen bilgilerin ayrı maddeler olarak ele alındığı orijinal formuna göre madde sayısı farklılaşmıştır.

Anketin orijinal dilinden Türkçeye uyarlanması, ilk olarak araştırmacılar tarafından, birbirinden bağımsız olarak gerçekleştirilmiştir. Ardından, çevirilerdeki farklılıklar üzerinde uzlaşıya varılarak ilk uyarlama gerçekleştirilmiştir. Anketin orijinal metni ile araştırmacılar tarafından hazırlanmış olan çeviri, üç yabancı dil uzmanı ve iki alan uzmanının görüşlerine sunularak, alınan geribildirimler doğrultusunda gerekli düzenlemeler yapılmıştır. Bu sürecin ardından Türkçe anket, anlatım ve dilbilgisi yönünden incelenmek üzere iki dilbilim uzmanının görüşlerine sunularak yeniden düzenlenmiştir. Son olarak anket, hedef grup tarafindan anlaşılırlığı değerlendirilmek üzere çalışma grubunda yer alan beş farklı unvandaki öğretim elemanlarından oluşacak şekilde seçilen beş kişilik bir grubun görüşlerine sunulmuştur. Yapılan bu pilot uygulama sırasında, anketin öğretim elemanları tarafindan tamamlanmasının ortalama yarım saat sürdüğü belirlenmiştir. Pilot uygulamaya katılan öğretim elemanlarından alınan öneriler doğrultusunda ankete son şekli verilerek denemeye hazır hale getirilmiştir. Anketin, güvenirliğinin belirlenmesi amacıyla Cronbach's Alfa iç tutarlılık değerlerine bakılmıştır. Nitel verilerin güvenirliği, veri dökümlerinin üç eğitim bilimleri uzmanı tarafindan, verilerin katılımcılardan beklenen yanıtları karşılayıp karşılamaması açısından incelenmesi yoluyla gerçekleştirilmiştir. Güvenirlik için Miles ve Huberman'ın (1994) The reliability of the data was measured using the Miles and Huberman's (1994) Görüş Birliği / (Görüş Birliği + Görüş Ayrıllğı) x 100 formülü kullanılmıştır. Güvenirlik \% 98 olarak hesaplanmıştır.

\section{BULGULAR}

$\mathrm{Bu}$ bölümde, Chi (2015) tarafından geliştirilen Çevrimiçi Öğretime Hazırbulunuşluk Anketi'nin Türkçeye uyarlanması sürecinde yapılan analizlere ve ölçme aracına ilişkin bulgulara yer verilmiştir. Anketteki nicel veriler sağlayan maddelerin güvenirliği için hesaplanan Cronbach's Alfa iç tutarlık katsayısı ,91 olarak bulunmuştur. Nitel verilerin analizinden elde edilen sonuçların alan uzmanları tarafından yapılan analizleri sonucunda, katılımcıların ankete verdikleri yanıtların, sorularda istenilen bilgileri doğrudan karşıladığı görülmüştür. Elde edilen bulgulara dayanarak, uyarlanan anketin Türkiye'deki yükseköğretim kurumlarında uygulanabilecek geçerli ve güvenilir bir ölçme aracı olduğu söylenebilir.

Ankette yer alan 31 maddenin 13 tanesi açık uçlu sorulardan oluşmaktadır. Bunun yanında, yapılandırılmış 13 diğer maddeye yönelik katılımcı görüşleri, Likert tipi beşli derecelendirme ölçeği kullanılarak alınmıştır. Derecelendirmeler, sorunun içeriğine göre farklı kategorilere sahiptir. Sözü edilen 13 madde, bazılarında birden fazla alt maddeyi içerdiğinden; yanıtlanması gereken toplam 39 sorudan oluşmaktadır. Bunların yanında, 2 maddede katılımcıların 
yapılandırılmış maddelere yüzde dilimleri belirtmeleri istenmiş; 1 madde evet ya da hayır şeklinde yapılandırılmış, kalan 2 maddede ise katılımcıların sunulan seçenekler arasından seçim/seçimler yapılması istenmiş̧ir. Ankette yer alan maddelerin hepsi birlikte değerlendirildiğinde, ölçme aracında toplam 63 seçenekli, 13 açık uçlu ve 2 tane de hazırlanmış maddeler içinden seçimler yapılarak yanıtlanacak sorular bulunmaktadır. Sorularda ve sunulan seçeneklerde, anketin orijinalindeki şekline sadık kalınmıştır. Bununla birlikte, üçüncü bölüm olan öğretim elemanlarına teknoloji desteği bölümünde, öğretim elemanlarına sunulan teknolojik olanaklar, araştırmanın gerçekleştirildiği üniversitede Uzaktan Eğitim Merkezi'nin sağladığı olanaklarla sınırlı olduğu için; maddeler buna uyum sağlayacak şekilde değiştirilmiştir. Anketin bu bölümü, ilgili kurumun olanakları çerçevesinde uyarlanabilir.

Anket; öğrenme öğretme süreci, sosyal bağ ve öğrenci katılımı, öğretim elemanlarına teknoloji desteği, ders tasarımı ve öğretimsel tasarım ve ölçme ve değerlendirme olmak üzere beş ayrı bölümden oluşmaktadır. Anketin öğrenme-öğretme süreci bölümünde, öğretim elemanlarının teknoloji kullanma konusundaki mevcut yeterlikleri, eğitimde çevrim içi teknolojileri kullanma konusundaki algiları ve onları bu teknolojileri kullanma konusunda motive edebilecek unsurları belirlemeye yönelik sorular bulunmaktadır. Sosyal bağ ve öğrenci katılımı bölümünde, öğretim elemanlarının çevrim içi öğretim etkinliklerinde öğrenciler arası etkileşimi nasıl sağlayacakları ve öğrencilerle aralarında nasıl bağ kuracaklarına dair alg1 ve yeterlikleri değerlendirilmektedir. Öğretim elemanlarına teknoloji desteği boyutunda öğretim etkinliklerinde teknolojiye yer verme durumları ve öğretim teknolojilerine yönelik altyapıları belirlenmeye çalışılmaktadır. Dördüncü bölüm olan, ders tasarımı ve öğretimsel tasarım boyutunda, öğretim elemanlarının derslerinde kullandıkları ögretim strateji, yöntem ve teknikler yanında, derslerinde çevrim içi teknolojilere yer verme durumları ve bu konudaki yeterlik düzeylerini belirlemeye yönelik maddeler bulunmaktadır. Ek olarak bu bölümde, öğretim elemanlarının sahip oldukları olanakların elvermesi halinde derslerinde kullanmak isteyebilecekleri donanım, yazılım ya da uygulamaları belirlemek de amaçlanmıştır. Son boyut olan ölçme ve değerlendirme bölümünde ise, öğretim elemanlarının öğrenci başarısını izleme ve değerlendirme süreçlerinde çevrim içi teknolojilerden yararlanma durumları belirlenmeye çalışılmıştır. Son olarak, öğretim elemanlarının anket içerisinde değinilmediğini düşündükleri ve ayrıca belirtmek istedikleri görüşleri olabileceği düşünülerek, eklemek istedikleri düşünceleri paylaşabilecekleri bir açık uçlu soruya yer verilmiștir.

\section{TARTIŞMA ve SONUÇ}

$\mathrm{Bu}$ araştırmada, Chi (2015) tarafından geliştirilen Çevrimiçi Öğretime Hazırbulunuşluk Anketi'nin Türkçeye uyarlanması amaçlanmıştır. Araştırmacılar tarafından birbirinden bağımsız olarak Türkçeye çevrilerek, farklılıklar üzerinde uzlaşıya varılarak düzenlenen anket, orijinali ile birlikte üç yabancı dil uzmanı ile iki eğitim bilimleri alan uzmanının görüşlerine sunulduktan sonra, yeniden düzenlenmiştir. Yeniden düzenlenen anket, anlatım ve dilbilgisi yönünden incelenmek üzere iki dilbilim uzmanının görüşlerine sunulmuş ve görüşler doğrultusunda gerekli düzenlemeler yapılmıştır. Ardından anketin, anlaşılırlığ 1 ve tamamlanma süresine dair çıkarımlarda bulunabilmek üzere, çalışma grubunda yer alan beş farklı unvandaki beş öğretim elemanlarından oluşacak şekilde seçilen bir grup üzerinde pilot uygulaması yapılmıştır. Pilot uygulama ardından öğretim elemanları ile görüşme yapılarak, alınan öneriler doğrultusunda ölçme aracına son şekli verilmiştir.

Anketin, güvenirliğinin belirlenmesi amacıyla Cronbach's Alfa iç tutarlılık değerleri hesaplanmış ve katsayı .91 olarak bulunmuştur. Nitel verilerin güvenirliği için üç eğitim bilimleri alan uzmanının görüşlerine başvurulmuştur. Uzmanlar, veri dökümlerini, elde edilen yanıtların sorularda istenen bilgileri içerip içermemesi açısından incelemiş ve açık uçlu soruların uyarlamalarının istenilen niteliği taşıdığı sonucuna ulaşılmıştır. Gerçekleştirilen çalışmadan elde edilen sonuçlara göre uyarlanan anketin, Türkiye'deki yükseköğretim kurumlarında uygulanabilecek geçerli ve güvenilir bir ölçme aracı olduğu söylenebilir.

Buna göre uyarlanan anket, öğretme öğrenme süreci, sosyal bağ ve öğrenci katılımı, öğretim elemanlarına teknoloji desteği, ders tasarımı ve öğretimsel tasarım ile ölçme ve değerlendirme olmak üzere beş ayrı bölümden oluşmaktadır. Öğretme-öğrenme süreci boyutu, 24 
seçenekli, 5 açık uçlu ve 2 soruda da hazırlanmış maddeler arasından seçimlerin yapılması gerektiği; sosyal bağ ve öğrenci katılımı boyutu, 5 seçenekli, öğretim elemanlarına teknoloji desteği boyutu, 14 seçenekli ve 2 açık uçlu; ders tasarımı ve öğretimsel tasarım boyutu 19 seçenekli ve 2 açık uçlu; ölçme ve değerlendirme boyutu ise 1 seçenekli ve 3 açık uçlu sorudan oluşmaktadır. Anket, içeriğinde ele alınan konular ile ilgili olarak öğretim elemanlarının belirtmek istedikleri düşüncelerini öğrenmek üzere hazırlanmış bir açık uçlu soru ile sonlanmaktadir.

Çevrimiçi Öğretime Hazırbulunuşluk Anketi, yükseköğretim kurumlarındaki fakülte, yüksekokul ya da bölümlerin çevrim içi öğretim konusunda öğretim elemanlarının hazırbulunuşluğunu, gereksinimlerini, sorunlarını belirleyebilmek üzere bir ihtiyaç analizi niteliğinde ya da yapılacak stratejik planlara veri sağlamak amacıyla kullanılabilir. Aynı zamanda anket, öğretim elemanlarının çevrim içi teknolojilerin eğitimde kullanımına yönelik algılarını ve onları bu teknolojilere derslerinde yer vermeleri amacıyla güdüleyecek unsurları da belirlemeye yönelik bilgiler sağlaması açısından, bu konuda yapılacak girişimlere yön verebilecek bir ölçme aracıdır. Anket öğretim elemanlarından oldukça kapsamlı bilgiler talep ettiğinden dolayı, tamamlanması uzun zaman alabilmektedir. Bu nedenle, uygulanması öncesinde ilgili bölüm ya da fakülte yönetimlerinin, ölçme aracının uygulanma amacına ve verilerin ne amaçla kullanılacağına dair bir bilgilendirme toplantısı yaparak öğretim elemanlarını bilgilendirmesi, gönüllü katılımın sağlanması açısından önemli görülmektedir. Ayrıca, anketin öğretim elemanlarına teknoloji desteği boyutunda yer alan maddeler, uygulamayı yapan yükseköğretim kurumuna özel bilgiler içerdiğinden, ilgili kurumun öğretim elemanlarına sunduğu teknolojik destek ve altyapılar kapsamında yeniden düzenlenmelidir. 


\section{KAYNAKLAR}

Adnan, M. (2012). So they think they are ready for distance learning..? Faculty members' attitude towards and their potential contribution to distance learning initiatives: Muğla Sitk1 Koçman University case. Proceedings of 4th International Future-Learning Conference on Innovations in Learning for the Future 2012: e-learning (ss. 405-438). İstanbul, Turkey: İstanbul University.

Adnan, M., \& Boz, B. (2015). Faculty members' perspectives on teaching mathematics online: Does prior online learning experience count?. Turkish Online Journal of Qualitative Inquiry, 6(1), 2138.

Akaslan, D., \& Law, E. L. C. (2011). Measuring teachers' readiness for e-learning in higher education institutions associated with the subject of electricity in Turkey. In Proceedings of 2011 IEEE Global Engineering Education Conference (EDUCON) içinde (ss. 481-490). New York: Institute of Electrical and Electronics Engineers, Inc.

Albion, P. R., Tondeur, J., Forkosh-Baruch, A., \& Peeraer, J. (2015). Teachers' professional development for ICT integration: Towards a reciprocal relationship between research and practice. Education and Information Technologies, 20(4), 655-673.

Allen, I. E., Seaman, J., Lederman, D., \& Jaschik, S. (2012). Conflicted: faculty and online education, 2012. https://www.insidehighered.com/sites/default/server_files/files/IHE-BSRG-Conflict.pdf adresinden 20.12.2016 tarihinde erişilmiştir.

Allen, I. E., Seaman, J., Poulin, R., \& Taylor Straut, T. (2016). Online report card: Tracking online education in the United States, 2015. Survey Report by Online Learning Consortium.

Bates, A.W. (2000). Managing technological change: Strategies for college and university leaders. Jossey-Bass.

Borotis, S., \& Poulymenakou, A. (2004). E-learning readiness components: key issues to consider before adopting e-learning interventions. In J. Nall, \& R. Robson (Eds.), Proceedings of World Conference on E-Learning in Corporate, Government, Healthcare, and Higher Education (2004) (ss. 1622-1629). Chesapeake, VA: Association for the Advancement of Computing in Education (AACE).

Chi, A. (2013). The journey to teaching online: A case study of faculty preparation and experiences in online teaching (Unpublished doctoral thesis). Social Science Research Network.

Chi, A. (2015). Development of the readiness to teach online scale (Unpublished master's thesis). University of Denver, CO, Electronic Theses and Dissertations. Paper 1018.

Çakır, Ö. \& Horzum, M.B. (2015). Öğretmen adaylarının çevrimiçi öğrenmeye hazırbulunuşluk düzeylerinin çeşitli değişkenler açısından incelenmesi. Eğitimde Kuram ve Uygulama, 11(1), 115.

Dada, D. (2006). E-Readiness for developing countries: Moving the focus from the environment to the users. The Electronic Journal on Information Systems in Developing Countries, 27(6), 1-14.

Gold, S. (2001). A constructivist approach to online training for online teachers. Journal of Asynchronous Learning Environments, 5(1), 35-57. 
Hoşgörür, T. (2011). What are the demands of the new millennium from students, learning environments and the curriculum? [Yeni milenyumun öğrencilerden, öğrenme ortamlarından ve öğretim programlarından talepleri nelerdir?]. Eğitim Bilimleri Araştırmaları Dergisi - Journal of Educational Sciences Research, 1(1), 123-134.

Hoşgörür, V. (2016). Views of primary school administrators on change in schools and change management practices. Kuram ve Uygulamada Eğitim Bilimleri, 16(6), 2029-2045.

Kaur, K., \& Abas, Z. W. (2004). An assessment of e-learning readiness at Open University Malaysia. In Proceedings of the International Conference on Computers in Education (ICCE). http://eprints.oum.edu.my/115/ adresinden 25.12.2016 tarihinde erişilmiştir.

Kaymak, Z.D. \& Horzum, M.B. (2013). Çevrimiçi öğrenme öğrencilerinin çevrimiçi öğrenmeye hazır bulunuşluk düzeyleri, algıladıkları yapı ve etkileşim arasındaki ilişki. Kuram ve Uygulamada Ĕ̈itim Bilimleri, 13(3), 1783-1797.

Knowles, M. (1984). The adult learner: A neglected species (3rd ed.). Houston, TX: Gulf

Lee, J. A., \& Busch, P. E. (2005). Factors relating to instructors' willingness to participate in distance education. Journal of Educational Research, 99(2), 109-115.

Lorenzetti, J. P. (2011). Motivating online faculty from the inside and the outside. Distance Education Report, 15(21), 1-8.

Madden, T. (2008). Planlı değişim sürecinin okulların geliştirilmesinde kullanılması (Yayınlanmamış doktora tezi). Eskişehir: Anadolu Üniversitesi Eğitim Bilimleri Enstitüsü.

Miles, M.B. \& Huberman, A.M. (1994). Qualitative Data Analysis. California: Sage Publishing.

Özgür, H. (2013). Uzaktan eğitim öğrencilerinin öğrenme stilleri: Trakya Üniversitesi örneği. Trakya Üniversitesi Eğitim Fakültesi Dergisi, 3(2), 85-91.

Palloff, R., \& Pratt, K. (2011). The excellent online instructor: Strategies for professional development. San Francisco, CA: Jossey-Bass.

Shraim, K. \& Khlaif, Z. (2010, Şubat). Students' readiness towards e-learning. A case study of virtual classrooms for secondary education in Palestine. 3rd Annual Forum on e-learning Excellence in the Middle East. Dubai. 1-4 Feb 2010.

Singleton, H. W., \& Session, C. L (2011). Faculty concerns related to distance learning within nontraditional doctoral programs. New Directions for Adult and Continuing Education, 2011(129), 31-41. doi: 10.1002/ace.398

Smith, P. J., Murphy, K. L., \& Mahoney, S. E. (2003). Towards identifying factors underlying readiness for online learning: An exploratory study. Distance Education, 24(1), 57-67. doi:10.1080/01587910303043.

Soydal, İ., Alır, G., \& Ünal, Y. (2012). Türk üniversiteleri e-öğrenmeye hazır mı? Hacettepe Üniversitesi Edebiyat Fakültesi Örneği. Prof. Dr. K. Gülbün Baydur'a Armağan içinde (ss. 133-144). Ankara: Hacettepe Üniversitesi Bilgi ve Belge Yönetimi Bölümü. 
Stein, S. J., Shephard, K., \& Harris, I. (2011). Conceptions of e-learning and professional development for e-learning held by tertiary educators in New Zealand. British Journal of Educational Technology, 42(1), 145-165.

Süer, İ., Kaya, Z., Bülbül, H. İ., Karaçanta, H., Koç, Z., \& Çetin, Ş. (2005). Gazi Üniversitesi'nin uzaktan eğitim potansiyeli. The Turkish Online Journal of Educational Technology, 4(1), 107113.

Tabata, L. N., \& Johnsrud, L. K. (2008). The impact of faculty attitudes towards technology, distance education and innovation. Research in Higher Education, 49, 625-646.

Totaro, M. W., Tanner, J. R., Noser, T., Fitzgerald, J. F., \& Birch, R. (2005). Faculty perceptions of distance education courses: A Survey. Journal of College Teaching \& Learning, 7(2), 13-20.

Warner, D., Christie, G., \& Choy, S. (1998). Readiness of VET clients for flexible delivery including online learning. Brisbane: Australian National Training Authority.

Watkins, R., Leigh, D., \& Triner, D. (2004). Assessing readiness for e-learning. Performance Improvement Quarterly, 17(4), 66-79.

Yağc1, M., Strakaya, D.A. \& Özüdoğru, G. (2015). The investigation of attitude and readiness of information and communication technologies pre-service teachers toward web based learning. Procedia-Social and Behavioral Sciences, 174, 1099-1106. 